\title{
Polydimethysiloxane Modified Silica Nanochannel Membrane for Hydrophobicity-Based Molecular Filtration and Detection
}

Xingyu Lin, Bowen Zhang, Qian Yang, Fei Yan, Xin Hua and Bin Su*

Corresponding Author:

Professor Dr. Bin SU

Institute of Analytical Chemistry

Department of Chemistry

Zhejiang University

Hangzhou 310058, China

E-mail:subin@zju.edu.cn

Homepage: http://mypage.zju.edu.cn/binsu

\section{Table of Contents}

Scheme S1. Molecular structures of studied probes

Figure S1. SEM characterization of PDMS modification

Figure S2. AFM characterization of PDMS modification

Figure S3. FTIR characterization of PDMS modification

Figure S4. ToF-SIMS characterization of PDMS modification

Figure S5. MALDI-ToF characterization of PDMS modification

Figure S6. XPS characterization of PDMS modification

Figure S7. Characterization of PDMS modification by water static contact angle measurements

Figure S8. CV study of molecular transport through nanochannels

Figure S9. Paraoxon transport through nanochannels

Figure S10. Molecular transport through ultrathin PDMS layer deposited on bare ITO electrodes

Figure S11. PDMS removal by calcination

Figure S12. Molecular transport in a multicomponent solution through nanochannels

Figure S13. Optimized conditions for OPs detection

Table S1. Analytical results for OPs detection

Table S2. Determination of paraoxon in real samples $(n=3)$ 
Scheme S1. Molecular structures of studied probes

Hydrophilic
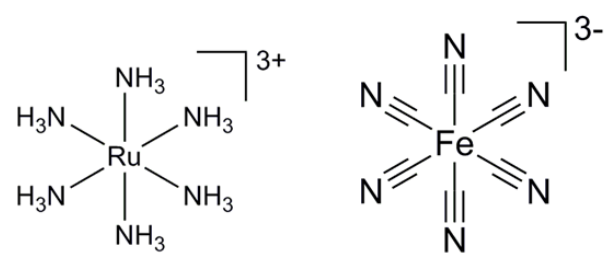

$\mathrm{Ru}\left(\mathrm{NH}_{3}\right)_{6}{ }^{3+}$

$\mathrm{Fe}(\mathrm{CN})_{6}{ }^{3-}$<smiles>NCCc1ccc(O)c(O)c1</smiles>

Dopamine

Hydrophobic

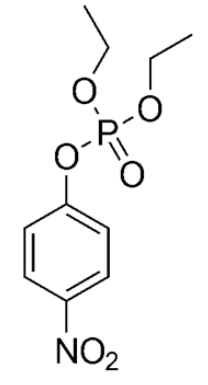

Paraoxon<smiles>Cc1c([N+](=O)[O-])cc([N+](=O)[O-])cc1[N+](=O)[O-]</smiles>

TNT

\section{Amphiphilic}

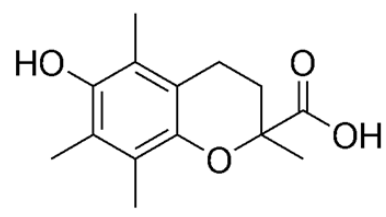

Trolox 


\section{Figure S1. SEM characterization of PDMS modification}
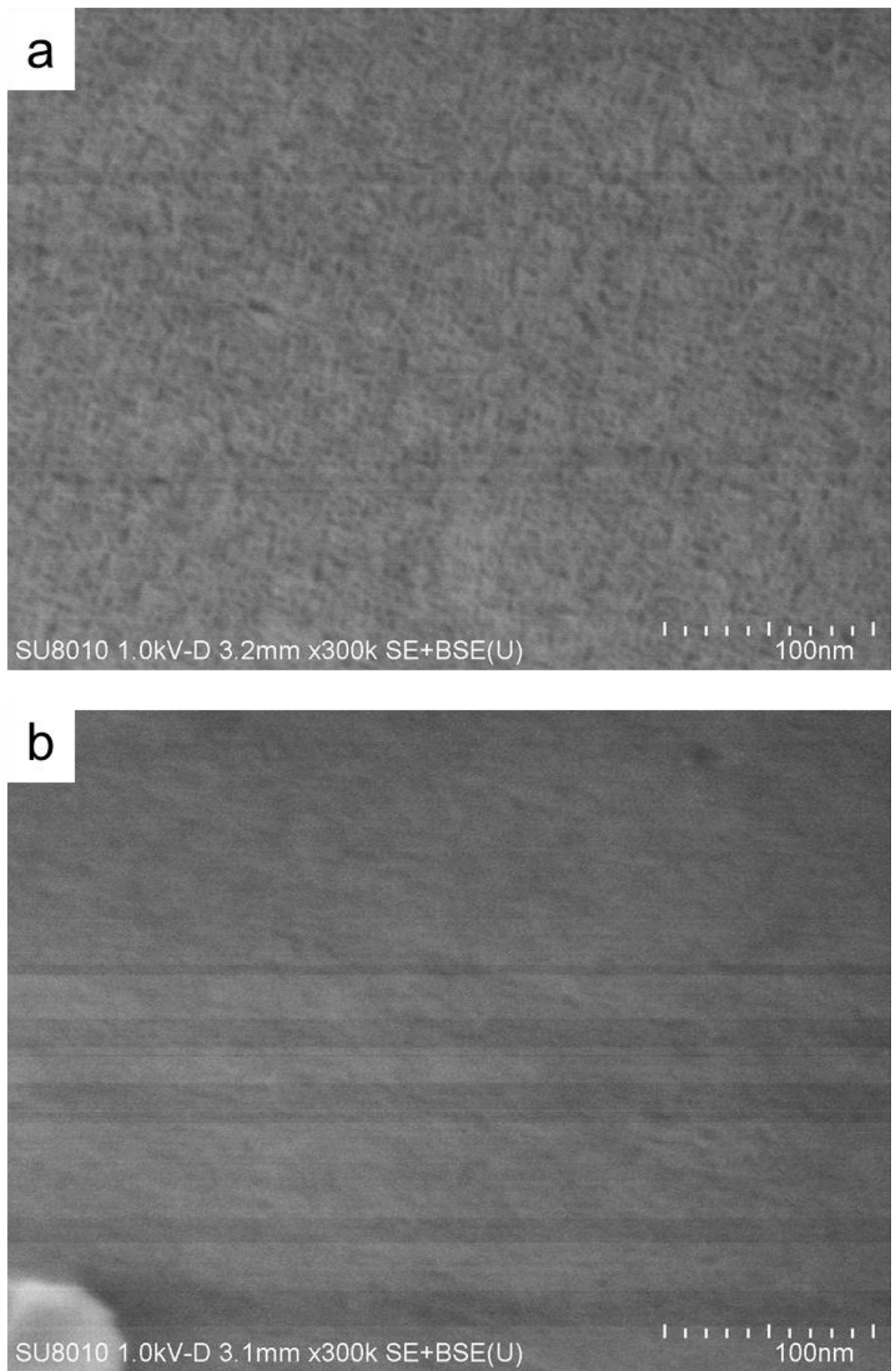

Figure S1. High-resolution SEM pictures of SNM before (a) and after (b) PDMS modification.

Before PDMS modification, we could found a high density of pores with a uniform pore size on the SNM (Figure S1a). However, after PDMS modification, a thin layer of PDMS was coated on the top surface, so that pores were hard to identify (Figure S1b). 
Figure S2. AFM characterization of PDMS modification
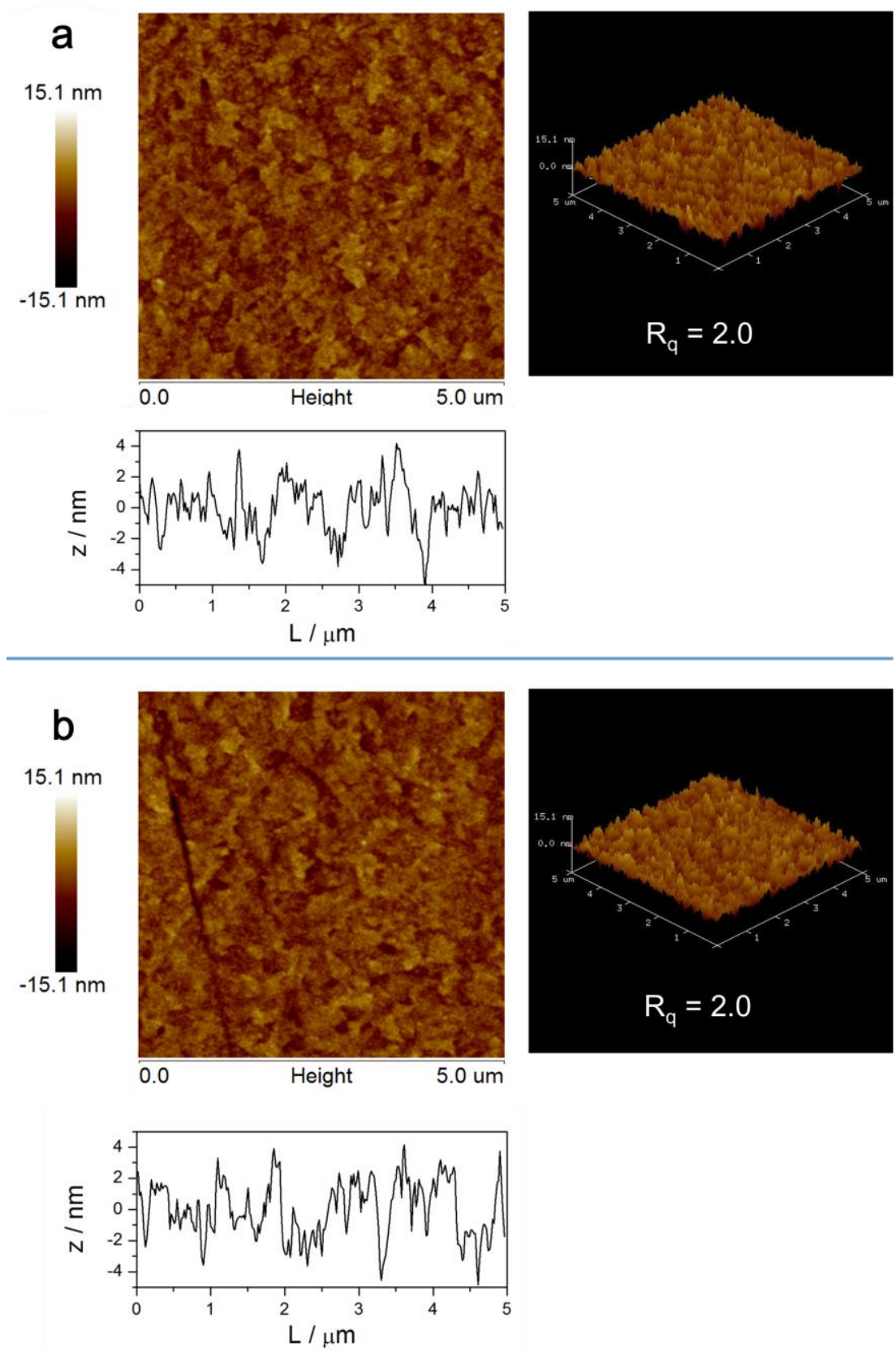

Figure S2. AFM images of SNM before (a) and after PDMS (b) modification. These images show their $2 \mathrm{D} / 3 \mathrm{D}$ topography and respective cross section views.

The morphology of SNM surface was shown in Figure S2a with a roughness Rq of 2.0. After PDMS modification, the morphology did not change much, and the roughness Rq was kept almost the same (Figure S2b). These results demonstrating that the PDMS modification is uniform. 


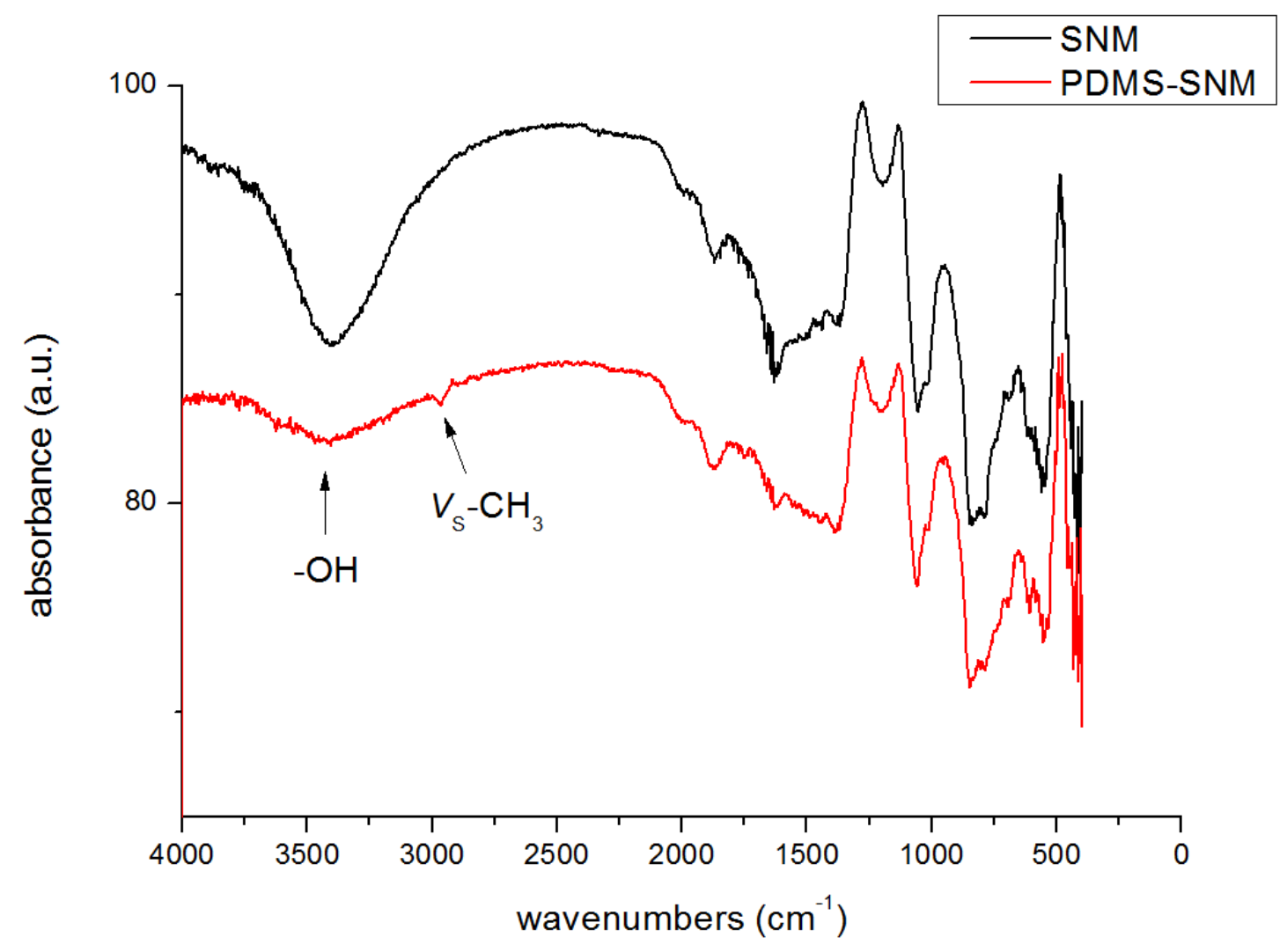

Figure S3. Specular reflection FTIR spectra of SNM and PDMS-SNM.

After PDMS modification, an absorption band appeared at $2964 \mathrm{~cm}^{-1}$, which can be ascribed to the vibration of $-\mathrm{CH}_{3}$ group. In addition, the absorption band of $-\mathrm{OH}$ at $3400 \mathrm{~cm}^{-1}$ was reduced after PDMS modification due to the reduced water adsorption or reduced surface Si-OH group by hydrophobic PDMS coating. 
Figure S4. ToF-SIMS characterization of PDMS modification
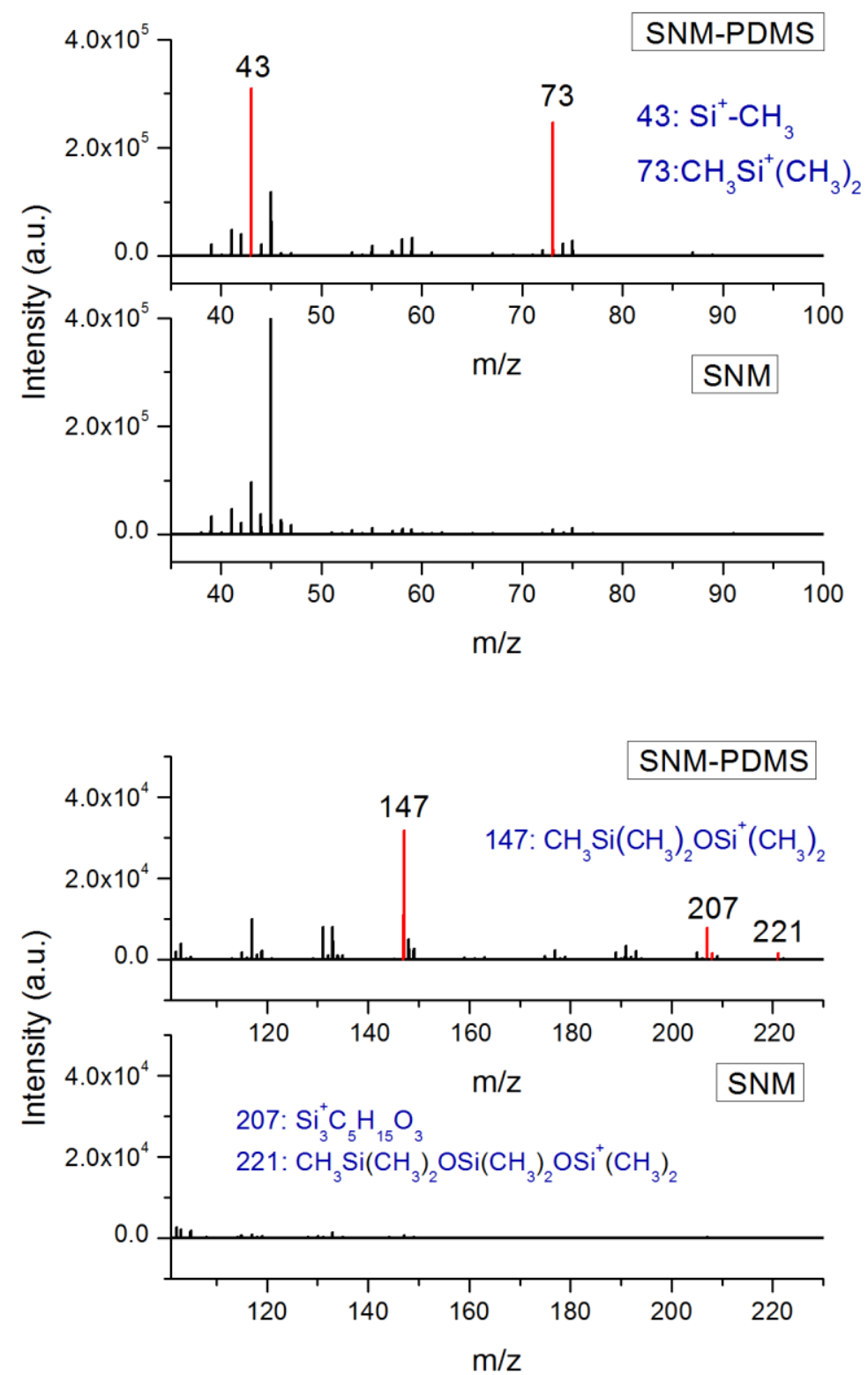

Figure S4. TOF-SIMS positive spectra of SNM before and after PDMS modification.

After PDMS modification, many characteristic $m /$ z peaks appeared, like $43\left(\mathrm{Si}^{+}-\mathrm{CH}_{3}\right), 73$ $\left(\mathrm{CH}_{3} \mathrm{Si}^{+}\left(\mathrm{CH}_{3}\right)_{2}\right), 147\left(\mathrm{CH}_{3} \mathrm{Si}\left(\mathrm{CH}_{3}\right)_{2} \mathrm{OSi}^{+}\left(\mathrm{CH}_{3}\right)_{2}\right), 207\left(\mathrm{Si}_{3}{ }^{+} \mathrm{C}_{5} \mathrm{H}_{15} \mathrm{O}_{3}\right)$ and 221

$\left(\mathrm{CH}_{3} \mathrm{Si}\left(\mathrm{CH}_{3}\right)_{2} \mathrm{OSi}\left(\mathrm{CH}_{3}\right)_{2} \mathrm{OSi}^{+}\left(\mathrm{CH}_{3}\right)_{2}\right)$, indicating the successful deposition of PDMS

(Figure S4). 
Figure S5. MALDI-ToF characterization of PDMS modification

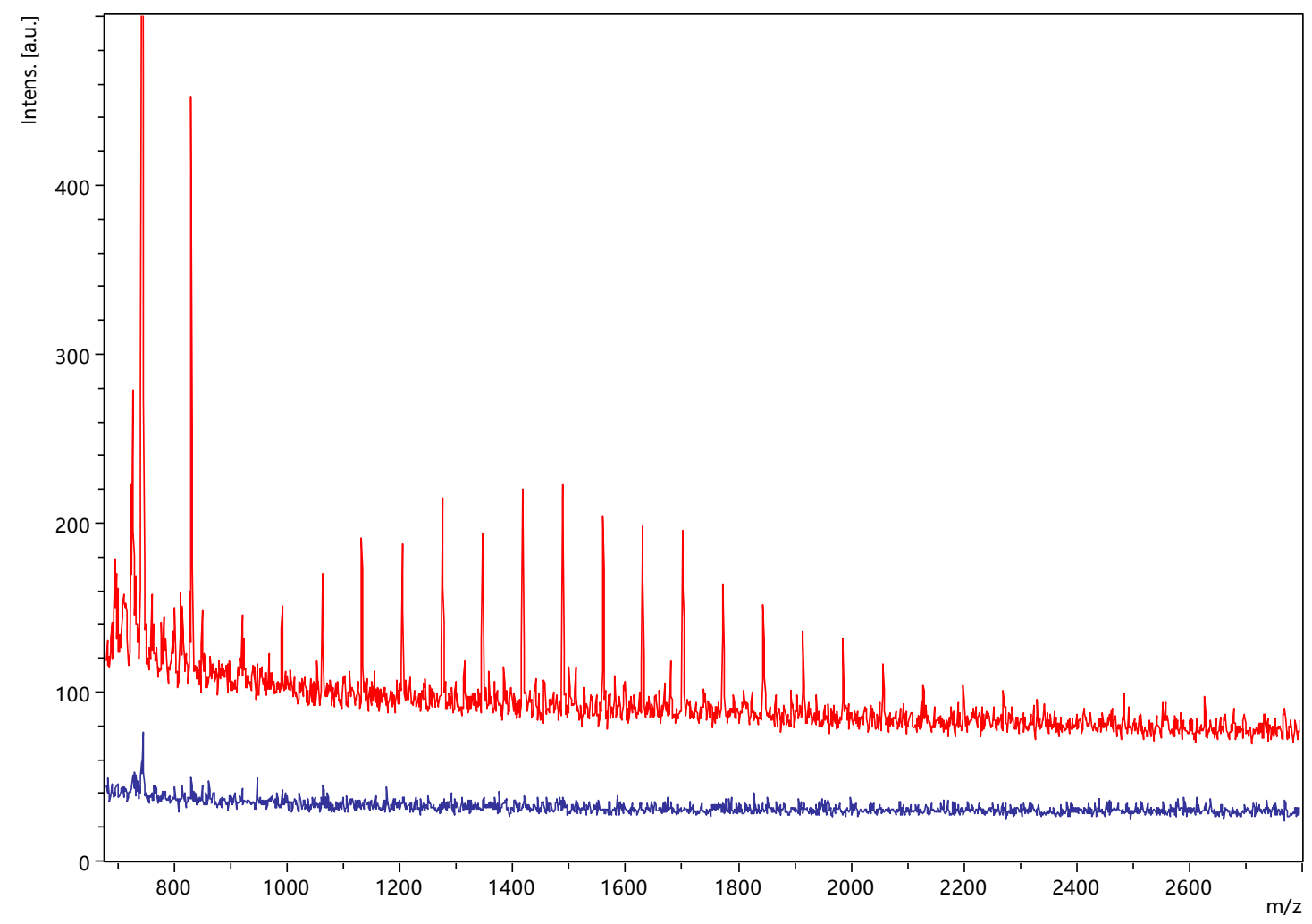

Figure S5. MALDI-ToF results of SNM before (blue line) and after (red line) PDMS modification

As shown in Figure S5, the size of PDMS chain deposited on the SNM ranges from 700 to $2200 \mathrm{kDa}$. 


\section{Figure S6. XPS characterization of PDMS modification}

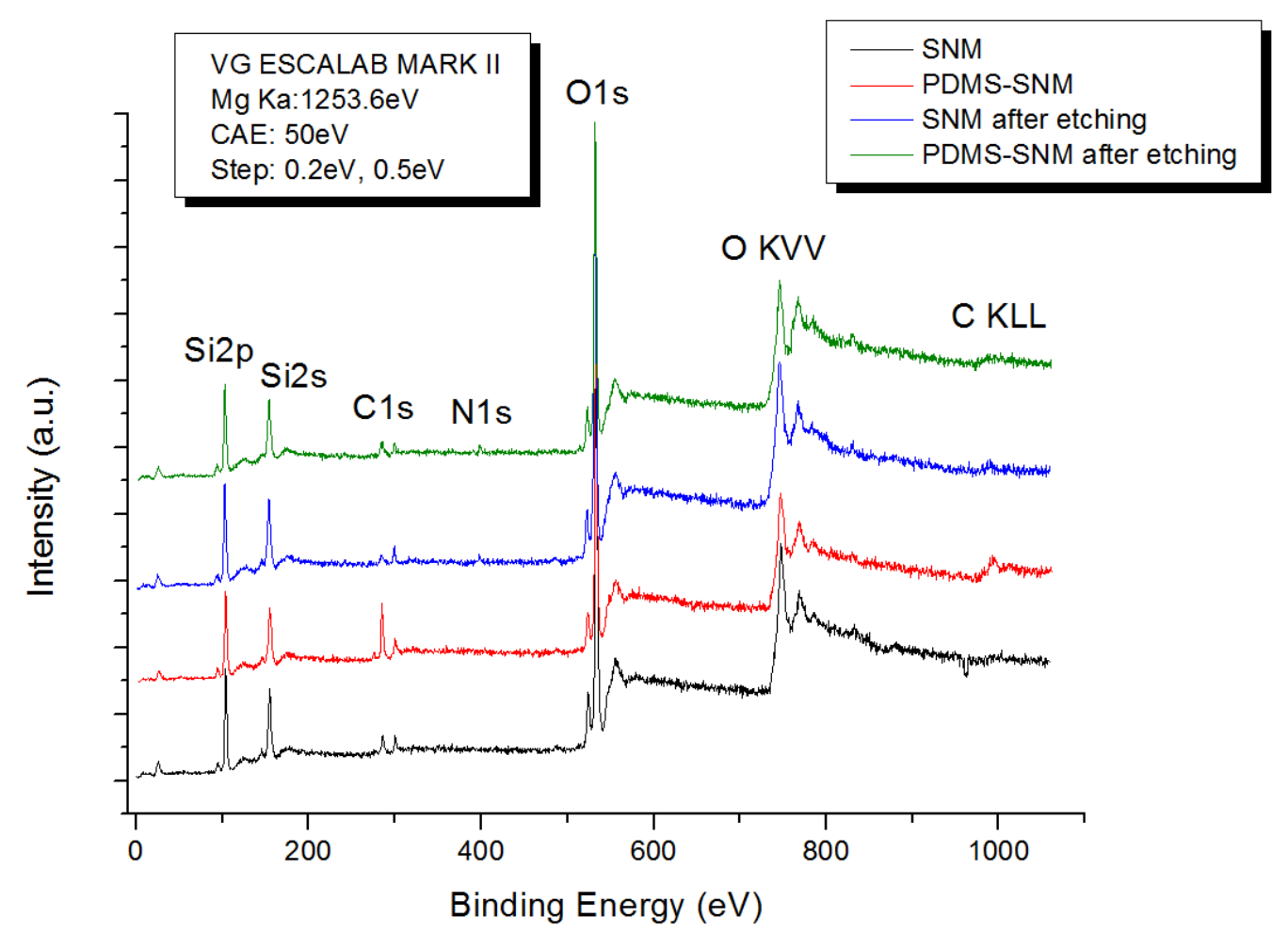

Figure S6. XPS spectra recorded for the SNM and PDMS-SNM. After initial data were collect, an $\mathrm{Ar}^{+}$sputtering beam with the energy of $3000 \mathrm{~V}$ was used to etch the top surface for $300 \mathrm{~s}$ for depth profiling.

The above XPS spectra show the presence of Si, C and O on the SNM. The existence of $\mathrm{C}$ may originate from the remaining CTAB molecules, the adsorption of organic pollutants or $\mathrm{CO}_{2}$ in nanochannels. Clearly, after PDMS modification, the $\mathrm{C} 1 \mathrm{~s} / \mathrm{Si} 2 \mathrm{p}$ ratio was increased from 0.18 to 0.52 due to the introduction of silicone component. After $\mathrm{Ar}^{+}$etching for $300 \mathrm{~s}$, the top part of the nanochannels was etched away, leading to a much reduced $\mathrm{C} / \mathrm{Si}$ ratio of about 0.16 . This value is similar with that of bare SNM after the same $\mathrm{Ar}^{+}$etching treatment (0.14). The low amount of $\mathrm{C}$ after etching may originate from the organic pollutants or the remaining CTAB molecules in the nanochannels (Note the "N" element appeared after etching, confirming the presence of CTAB). These results clearly demonstrated that the PDMS was only deposited on the top part of the nanochannels, as illustrated in Scheme 1. 
Figure S7. Characterization of PDMS modification by water static contact angle measurements

\begin{tabular}{|c|c|c|c|}
\hline & ITO & Silica glass & ITO-SNM \\
\hline Bare & $16^{\circ}$ & $18^{\circ}$ & $26^{\circ}$ \\
\hline $\begin{array}{c}\text { PDMS } \\
\text { Modification }\end{array}$ & $93^{\circ}$ & $91^{\circ}$ & $53^{\circ}$ \\
\hline
\end{tabular}

Figure S7. Water static contact angle images of bare ITO, silica glass and SNM before and after PDMS modification.

As shown in Figure S7, the water static contact angle of the ITO supported SNM was increased from 26 to $53^{\circ}$ after PDMS modification. It was smaller than that of bare ITO or silica glass after the same modification. This is most probably ascribed to the heterogeneous nanochannel structure with a hydrophobic layer on the top and pristine hydrophilic surface on the bottom. Although there are a hydrophobic PDMS layer on the top part, water molecules can still permeate this layer to enter the nanochannels, leading to the reduced water contact angle. It has been previously reported that water can penetrate from the hydrophobic side to the hydrophilic side in the asymmetrical hydrophobic/hydrophilic nanochannels. ${ }^{1-4}$ This scenario is also reasonable as all the following voltammetry measurements with appropriate redox probes yielded well-defined current responses. 
Figure S8. CV study of molecular transport through nanochannels
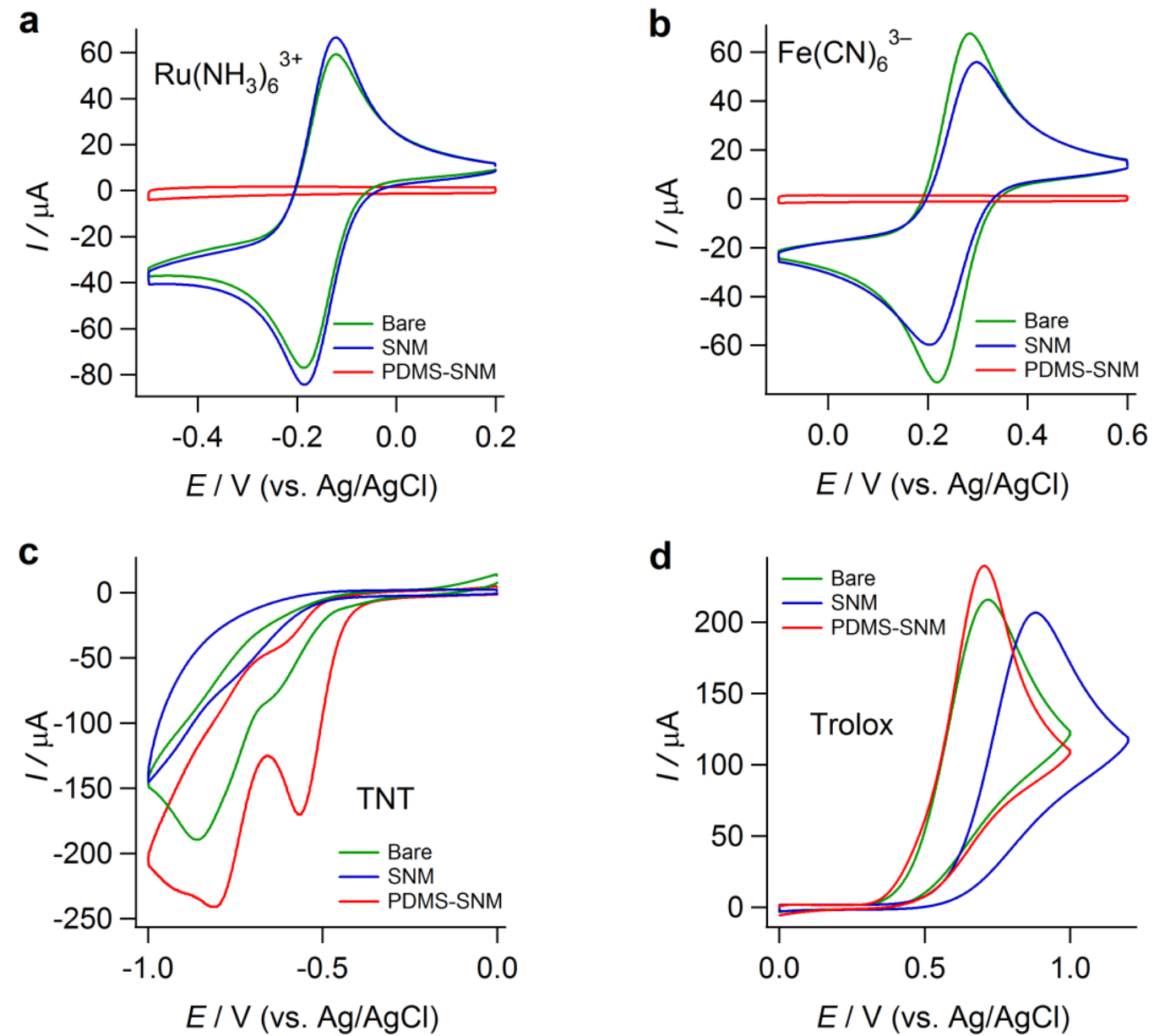

Figure S8. CV studies of molecular transport through silica nanochannels and PDMS modified nanochannels: (a) $\mathrm{Ru}\left(\mathrm{NH}_{3}\right)_{6}{ }^{3+}$, (b) $\mathrm{Fe}(\mathrm{CN})_{6}{ }^{3-}$, (c) TNT and (d) Trolox. In all cases, the $\mathrm{CV}$ response of a bare ITO is also compared. The electrolyte solution used here was $0.5 \mathrm{M} \mathrm{NaCl}$.

Corresponding to the DPV curves shown in Figure 2a-d in the manuscript. 
Figure S9. Paraoxon transport through nanochannels
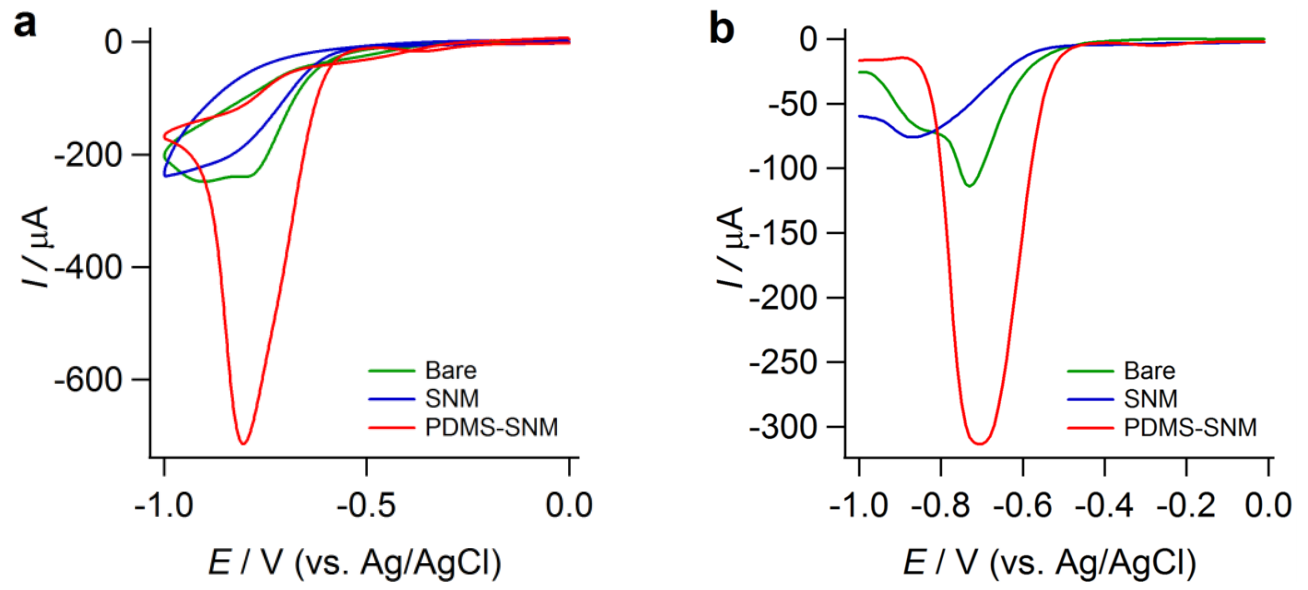

Figure S9. (a) CV and (b) DPV studies of paraoxon transport through silica nanochannels and PDMS modified silica nanochannels. The response of a bare ITO is also compared in both cases. The electrolyte solution used here was $0.5 \mathrm{M} \mathrm{NaCl}$. The concentration of paraoxon used here was $100 \mu \mathrm{M}$. 
Figure S10. Molecular transport through ultrathin PDMS layer deposited on bare ITO electrodes
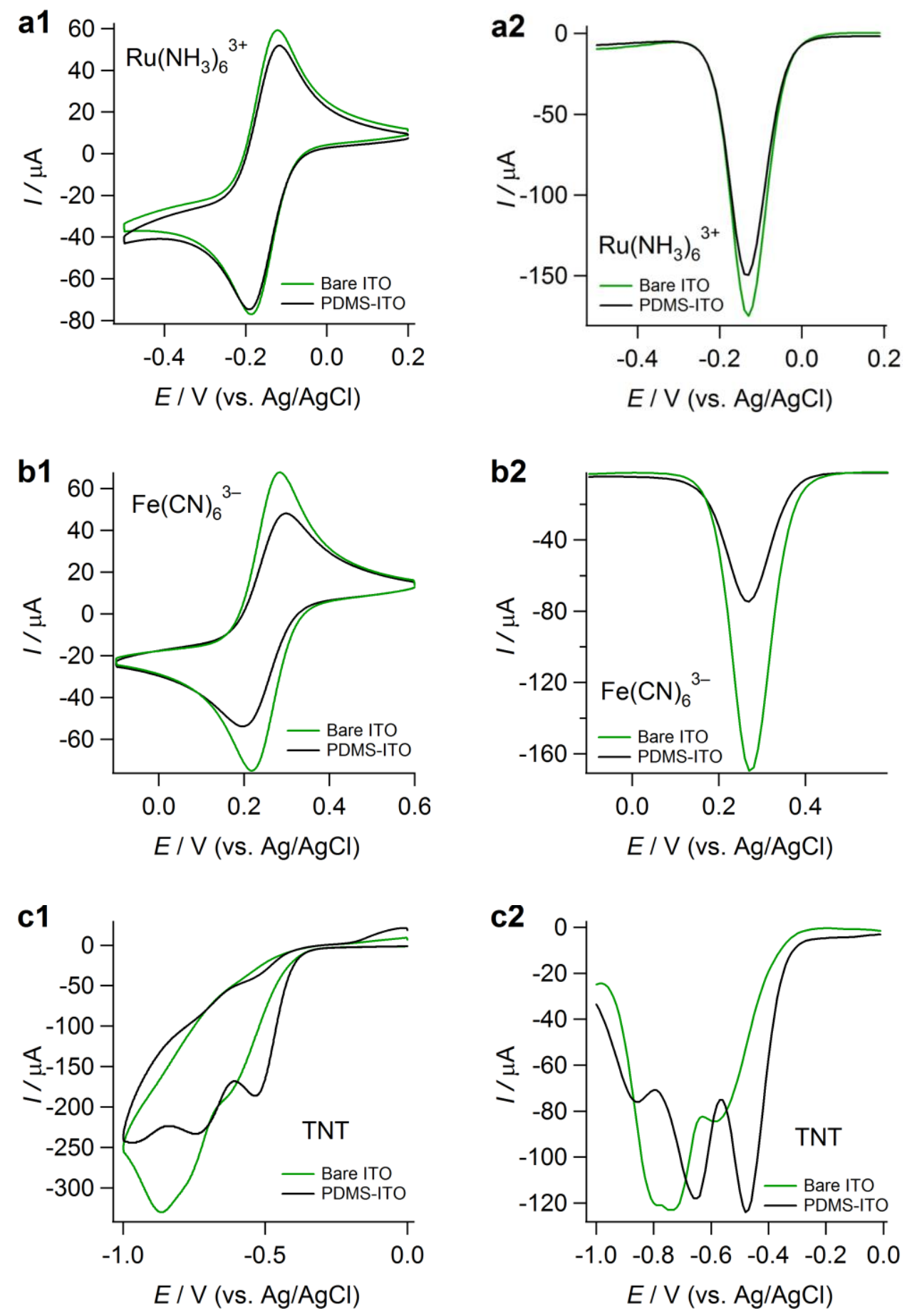

(continued next page) 

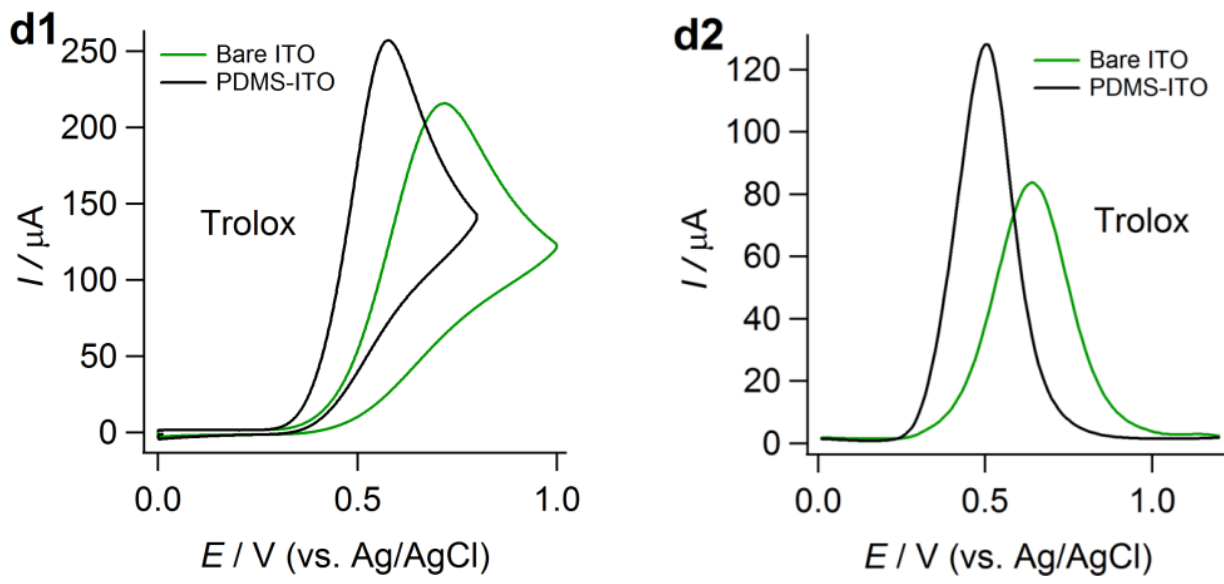

Figure S10. (a1, b1, c1 and d1) CV and (a2, b2, c2 and d2) DPV responses of ITO modified with an ultrathin PDMS layer: (a) $\mathrm{Ru}\left(\mathrm{NH}_{3}\right)_{6}{ }^{3+}$, (b) $\mathrm{Fe}(\mathrm{CN})_{6}{ }^{3-}$, (c) TNT, (d) Trolox. In all case, the response of a bare ITO is also compared. The electrolyte solution used here was $0.5 \mathrm{M} \mathrm{NaCl}$. From these results, it is clear that the PDMS layer does not significantly influence the molecular transport.

For comparison, PDMS was also deposited on the bare ITO glass using the same method and molecular transport through this ultrathin PDMS layer was investigated. In all cases, obvious voltammetric current waves were displayed for each redox probes. The influence of ultrathin PDMS layer on the molecular transport was not so significant as that observed with PDMS-SNM. For example, the CV curves of $\mathrm{Ru}\left(\mathrm{NH}_{3}\right)_{6}{ }^{3+}$ at the bare ITO and PDMS modified ITO are almost identical.

These results demonstrated that the PDMS hydrophobic layer itself is not the sole reason for the excellent permselectivity displayed by the PDMS-SNM. It is most probably associated with heterogeneous structure consisting of both hydrophobic PDMS layer and hydrophilic silica nanochannels. We suppose that the ultrasmall silica nanochannels serve as rigid scaffolds and PDMS deposit not only on the outer surface of the nanochannels but also on the inner surface of the nanochannels as shown in the Scheme 1. These hydrophobic PDMS chains on the inner surface of the nanochannels could effectively hinder the transport of hydrophilic ones while favor that of hydrophobic ones. 
Figure S11. PDMS removal by calcination

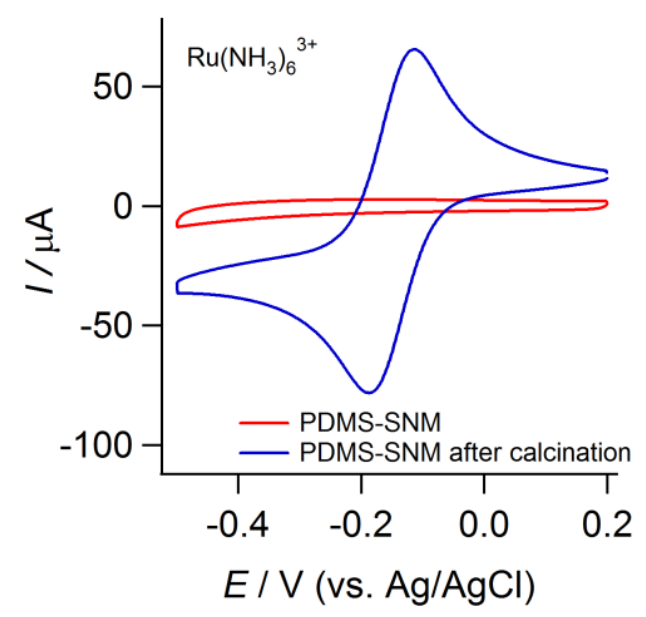

Figure S11. CV studies of $\mathrm{Ru}\left(\mathrm{NH}_{3}\right)_{6}{ }^{3+}$ transport through PDMS modified nanochannels before and after calcination at $390{ }^{\circ} \mathrm{C}$ for $6 \mathrm{~h}$. FTO glass was used here as the electrode. The electrolyte solution used here was $0.5 \mathrm{M} \mathrm{NaCl}$. 
Figure S12. Molecular transport in a multicomponent solution through nanochannels

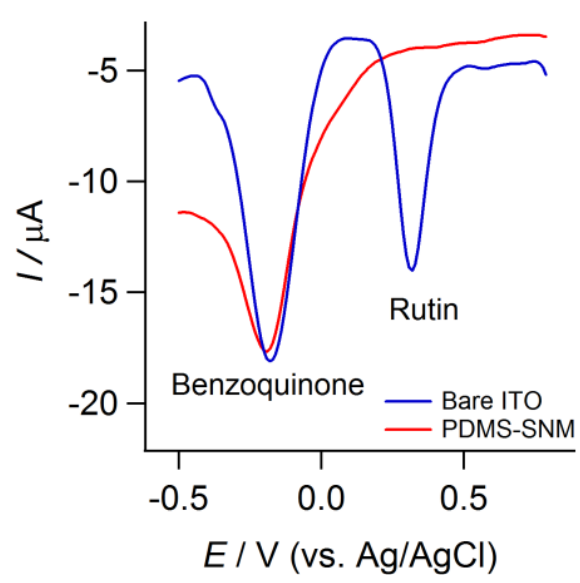<smiles>O=C1C=CC(=O)C=C1</smiles>

Benzoquinone $\mathrm{d}=0.6 \mathrm{~nm}$

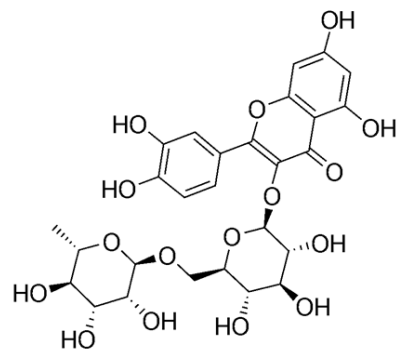

Rutin $\mathrm{d}=1.5 \mathrm{~nm}$

Figure S12. DPV studies of molecular transport through silica nanochannels and PDMS modified nanochannels in a multicomponent solution with different size. The solution was composed of benzoquinone and rutin.

As shown in Figure S12. rutin and benzoquinone are both hydrophobic molecules but different in size. The former molecule $(1.5 \mathrm{~nm})$ is larger than latter one $(0.6 \mathrm{~nm})$. Thus, PDMS modified silica nanochannels could selectively transport the small one while completely hinder that of the large. 
Figure S13. Optimized conditions for OPs detection
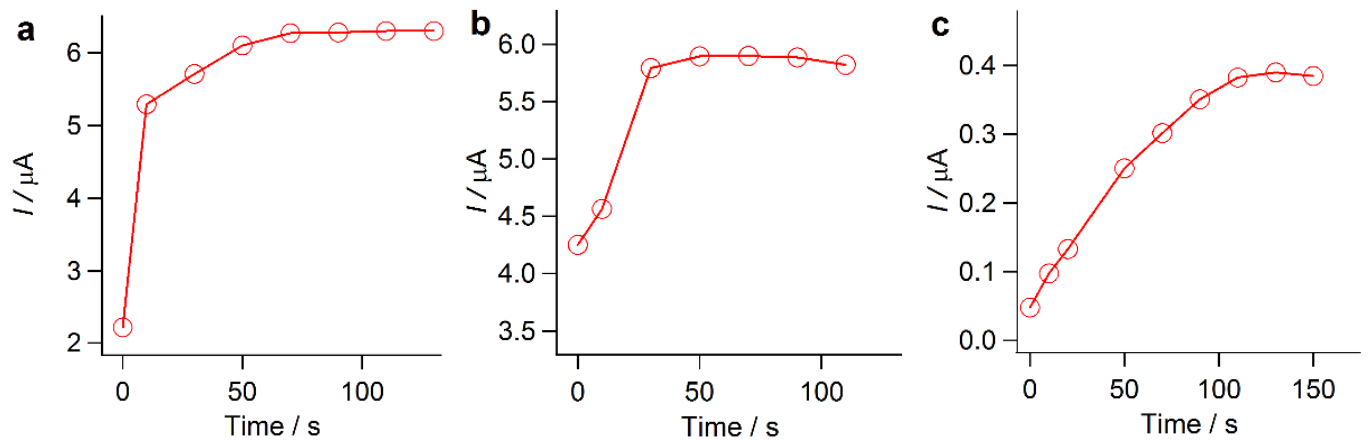

Figure S13. (a-c) Influence of the stirring time on the current response of $500 \mathrm{ppb}$ paraoxon (a), $500 \mathrm{ppb}$ methyl parathion (b) and $500 \mathrm{ppb}$ fenitothion (c) in $0.5 \mathrm{M} \mathrm{NaCl}$ solution.

Figure S13a-c show the influence of stirring time on the current response of $500 \mathrm{ppb}$ paraoxon (Figure S13a), 500 ppb methyl parathion (Figure S13b) and $500 \mathrm{ppb}$ fenitrothion (Figure S13c) in $0.5 \mathrm{M} \mathrm{NaCl}$ solution. The optimised stiring time is $70 \mathrm{~s}$ for paraoxon, $50 \mathrm{~s}$ for methy parathion and $110 \mathrm{~s}$ for fenitrothion. 
Table S1. Analytical results for OPs detection

\begin{tabular}{lcccc}
\hline \multicolumn{1}{c}{ OPs } & $\begin{array}{c}\text { Sensitivity } \\
(\mu \mathrm{A} / \mathrm{ppm})\end{array}$ & $\begin{array}{c}\text { Dynamic range } \\
(\mathrm{ppb})\end{array}$ & LOD $(\mathrm{ppb})$ & $\mathrm{R}$ \\
\hline paraoxon & 16.3 & $5-1000$ & 1.83 & 0.9999 \\
\hline methyl parathion & 11.6 & $5-1000$ & 2.59 & 0.9992 \\
\hline \multirow{2}{*}{ fenitrothion } & 0.76 & $50-600$ & 17.2 & 0.9966 \\
& 0.48 & $600-2000$ & & 0.9992 \\
\hline
\end{tabular}

Table S2. Determination of paraoxon in real samples $(n=3)$

\begin{tabular}{cccccc}
\hline Analyte & Sample & $\begin{array}{c}\text { Added } \\
(\mathrm{ppm})\end{array}$ & $\begin{array}{c}\text { Found } \\
(\mathrm{ppm})\end{array}$ & $\begin{array}{c}\text { Recovery } \\
(\%)\end{array}$ & $\begin{array}{c}\text { RSD } \\
(\%)\end{array}$ \\
\hline paraoxon & milk & 1.00 & 0.93 & 93 & 0.6 \\
\hline
\end{tabular}




\section{References}

1. Guo, W.; Tian, Y.; Jiang, L. Asymmetric Ion Transport through Ion-ChannelMimetic Solid-State Nanopores. Acc. Chem. Res. 2013, 46, 2834-2846.

2. Chen, Q.; Meng, L.; Li, Q.; Wang, D.; Guo, W.; Shuai, Z.; Jiang, L. Water Transport and Purification in Nanochannels Controlled by Asymmetric Wettability. Small 2011, 7, 2225-31.

3. Wang, H.; Ding, J.; Dai, L.; Wang, X.; Lin, T. Directional Water-Transfer through Fabrics Induced by Asymmetric Wettability. J. Mater. Chem. 2010, 20, 7938.

4. Wu, J.; Wang, N.; Wang, L.; Dong, H.; Zhao, Y.; Jiang, L. Unidirectional WaterPenetration Composite Fibrous Film Via Electrospinning. Soft Matter 2012, 8, 5996. 